\title{
Haemolytic uremic syndrome following fire ant bites
}

\author{
Yi-Che Lee ${ }^{1,2}$, Jyh-Seng Wang ${ }^{3}$, Jeng-Chuan Shiang ${ }^{4}$, Ming-Kai Tsai ${ }^{4}$, Kai-Tai Deng ${ }^{1}$, Min-Yu Chang ${ }^{1}$, Hsi-Hao Wang ${ }^{1}$, \\ Li-Chun $\mathrm{Ho}^{1,2}$, Yi-Ting Chen ${ }^{1}$ and Shih-Yuan Hung ${ }^{1 *}$
}

\begin{abstract}
Background: Haemolytic-uremic syndrome (HUS) is a severe, life-threatening disease with symptoms such as haemolytic anaemia, renal failure, and a low platelet count. Possible aetiology includes bacterial infections, medication, post-hematopoietic cell transplantation, pregnancy, autoimmune disease, and acquired immunodeficiency syndrome.

Case presentation: We report the case of a 21-year-old healthy man who developed acute renal failure caused by HUS. Typical symptoms of HUS combined with severe uraemia developed following a large local reaction after suspected Solenopsis invicta (fire ant) bites. He was successfully treated with plasma exchange and achieved complete recovery of renal function.

Conclusion: This is the first case illustrating a serious systemic reaction of HUS to fire ant bites, and highlights this severe complication in patients who sustain fire ant bites.
\end{abstract}

Keywords: Fire ant, Haemolytic-uremic syndrome, Plasma exchange, Renal failure, Venomous insects

\section{Background}

Haemolytic-uremic syndrome (HUS) is a disease commonly preceded by $E$. coli $\mathrm{O} 157: \mathrm{H} 7$ or other Shiga toxinproducing bacterial infections, medication (chemotherapy agents, cyclosporine, tacrolimus, quinine, ticlopidine, clopidogrel, oral contraceptives, valacyclovir, etc.), posthaematopoietic cell transplantation, pregnancy, autoimmune diseases (antiphospholipid antibody syndrome, systemic lupus erythematous, scleroderma renal crisis), acquired immunodeficiency syndrome, and idiopathic form of HUS [1].

To the best of our knowledge, there is currently no report establishing the relationship between HUS and red fire ant bites. Koya et al. reported a case of rhabdomyolysis and acute renal failure after fire ant bites, but no presentation of HUS was noted [2]. In our case, a 21-year-old man developed acute renal failure and HUS following a large local reaction on the left arm resulting from fire ant bites. This unusual case demonstrates a close relationship between HUS and fire ant bites. We

\footnotetext{
* Correspondence: ed100367@edah.org.tw

${ }^{1}$ Division of Nephrology, Department of Internal Medicine, E-Da Hospital/ I-Shou University, No.1, Yida Rd., Yanchao Dist., Kaohsiung City 824, Taiwan

Full list of author information is available at the end of the article
}

discuss the mechanisms of HUS caused by fire ant venom in detail.

\section{Case presentation}

A 21-year-old healthy male solider was stationed at a seed troop with the task of eradicating fire ants for 1 year. He was bitten by ants that were highly suspected to be fire ants, 2 weeks before hospital admission. Immediate flare and wheal developed over the left arm, followed by erythematous, oedematous, and indurated reactions. A spiking fever occurred in 2 days. He received medical attention at a local clinic, and the local reaction subsided gradually. However, 5 days later, he developed severe nausea and vomiting. His urine output also gradually decreased. He visited a local hospital for treatment, where he was administered intravenous fluids and medication including acetaminophen and metoclopramide, but no improvement was noted. Thereafter, the patient was transferred to our hospital.

On presentation, physical examination revealed a pulse rate of 75 beats $/ \mathrm{min}$, blood pressure of $150 / 84 \mathrm{mmHg}$, body temperature of $37.0^{\circ} \mathrm{C}$, and respiratory rate of 20 breaths/min. The pertinent positive findings included mild obesity (body mass index, $28.2 \mathrm{~kg} / \mathrm{m}^{2}$ ) and pale 
conjunctivae. No oedema, icteric sclera, abdominal mass, or palpably enlarged kidney was noted.

Laboratory data on admission showed the following values: serum sodium, $128 \mathrm{mEq} / \mathrm{L}$; potassium, $3.9 \mathrm{mEq} / \mathrm{L}$; urea nitrogen, $153 \mathrm{mg} / \mathrm{dL}$; creatinine, $20.1 \mathrm{mg} / \mathrm{dL}$; calcium, $8.4 \mathrm{mg} / \mathrm{dL}$; phosphorus, $3.9 \mathrm{mg} / \mathrm{dL}$; albumin, $4.2 \mathrm{~g} / \mathrm{dL}$; aspartate aminotransferase, $127 \mathrm{U} / \mathrm{L}$; alanine aminotransferase, $36 \mathrm{U} / \mathrm{L}$; total bilirubin, $2.0 \mathrm{~g} / \mathrm{dL}$; direct bilirubin, $0.5 \mathrm{~g} / \mathrm{dL}$; uric acid, $19.1 \mathrm{~g} / \mathrm{dL}$; myoglobin, $422 \mathrm{ng} / \mathrm{mL}$; lactate dehydrogenase, $3400 \mathrm{U} / \mathrm{L}$; creatine kinase (CK), $503 \mathrm{U} / \mathrm{L}$; CK-MB, $10.1 \mathrm{ng} / \mathrm{mL}$; troponin, $0.01 \mu \mathrm{g} / \mathrm{L}$; and haptoglobin $<7.0 \mathrm{mg} / \mathrm{dL}$. Arterial blood gases revealed a $\mathrm{pH}$ of 7.27, pCO2 of $41 \mathrm{mmHg}, \mathrm{pO} 2$ of $91 \mathrm{mmHg}$, oxygen saturation of $97.4 \%$, and bicarbonate level of $18 \mathrm{mEq} / \mathrm{L}$. Complete blood count (CBC) showed the levels of haemoglobin at $7.3 \mathrm{~g} / \mathrm{dL}$, white blood cells (WBC) at $8.8 \times 10^{3} / \mu \mathrm{L}$, platelets at $57 \times 10^{3} / \mu \mathrm{L}$, and a high reticulocyte level at $6.8 \%$. WBC differential count showed neutrophils at $79.5 \%$, eosinophils at $2.7 \%$, basophils at $0.4 \%$, and monocytes at $6.8 \%$. Both prothrombin time and partial thromboplastin time were within normal ranges. Direct and indirect Coombs tests were both negative. A peripheral blood smear revealed 2-3 schistocytes per high-power field (Figure 1). Immunoglobulin (Ig) G, IgA, and IgM levels were all within normal ranges, but IgE level was high at $408.0 \mathrm{IU} / \mathrm{mL}$. Serum complement showed the C3 level at $102 \mathrm{mg} / \mathrm{dL}$ (normal range, $90-180 \mathrm{mg} / \mathrm{dL}$ ), and the $\mathrm{C} 4$ level at $22.6 \mathrm{mg} / \mathrm{dL}$ (normal range, $10-40 \mathrm{mg} / \mathrm{dL}$ ). The serum antinuclear antibody level was within the normal range. Results for venereal disease research laboratory/rapid plasma reagin test, hepatitis B surface antigen (HBsAg), hepatitis C, and human immunodeficiency virus antibodies were all negative. Urinalysis revealed dark brown urine with $3+$ protein, $0-3$ red blood cells, and 3-5 white blood cells per high-power field, with positive results for haemoglobin. Renal ultrasound showed increased echogenicity (grade I) in

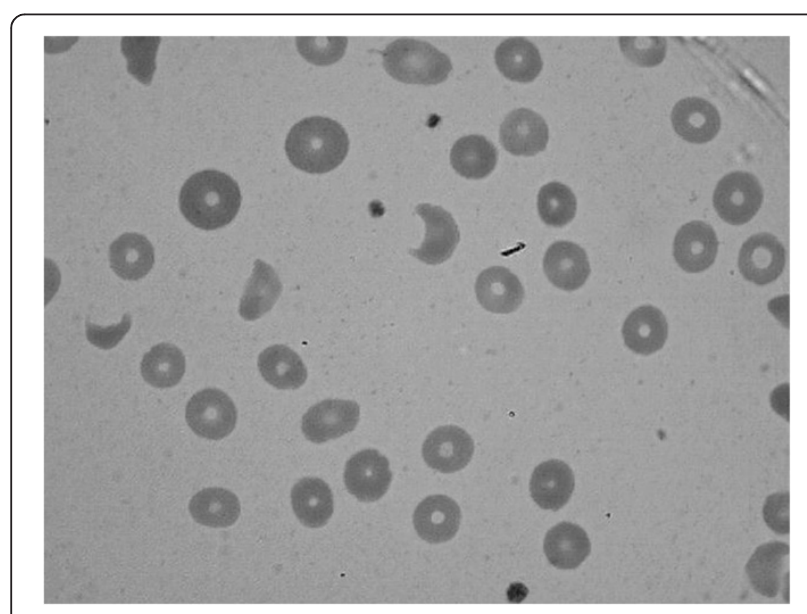

Figure 1 Peripheral blood smear showing some schistocytes. both kidneys with right and left renal size at $12.4 \times$ $5.45 \mathrm{~cm}$ and $12.5 \times 5.4 \mathrm{~cm}$, respectively.

The patient was diagnosed with acute renal failure secondary to HUS and treated with plasma exchange with one plasma volume per day for a total of 6 days. Haemodialysis was also initiated for oliguria and uremic symptoms, including nausea, vomiting, and dyspnoea. The patient received haemodialysis therapy every second day for a total of 6 sessions. Blood cultures for bacteria and stool culture for E. coli $\mathrm{O} 157$ were negative. An echoguided renal biopsy was performed on day 7 of admission. Pathological examination showed a partially collapsed glomerulus, endothelial cell swelling, subendothelial widening with fluffy material, and double-contour formation of the glomerular basement membrane, compatible with HUS (Figure 2). After plasma exchange, haemodialysis, and supportive treatment, the patient's urine output and renal function continued to improve. At the same time, haemolytic anaemia and thrombocytopenia also gradually improved and dialysis was terminated on the day 8 of admission. Finally, the patient was discharged with a creatinine level of $1.9 \mathrm{mg} / \mathrm{dL}$ (Figure 3).

On follow-up examination 1 month after discharge, the patient was in good health with normal renal function and $\mathrm{CBC}$. Because of persistent hypertension (blood pressure around 140/90 $\mathrm{mmHg}$ ), he was still on antihypertensive drugs (amlodipine $5 \mathrm{mg}$ OD, carvedilol $25 \mathrm{mg}$ OD) 1 year after discharge.

\section{Discussion}

Historically, the red fire ant S. invicta was imported from South America into North America, residing in the soil of potted plants that were shipped in the 1930s. Since approximately the year 2000 , the imported fire ant (IFA) has also been found in China and Taiwan. It belongs to the insect order Hymenoptera, which includes

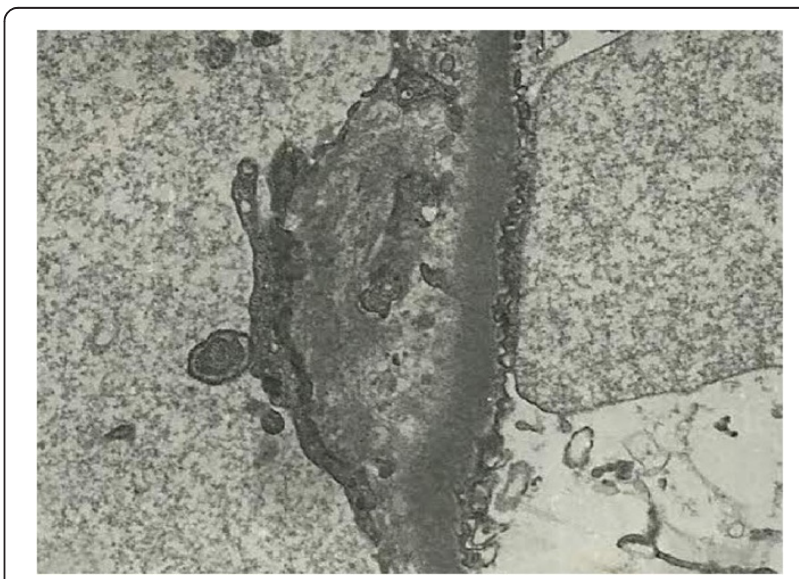

Figure 2 Electron microscopy of renal biopsy shows subendothelial widening with fluffy material and double contour formation of the glomerular basement membrane. 


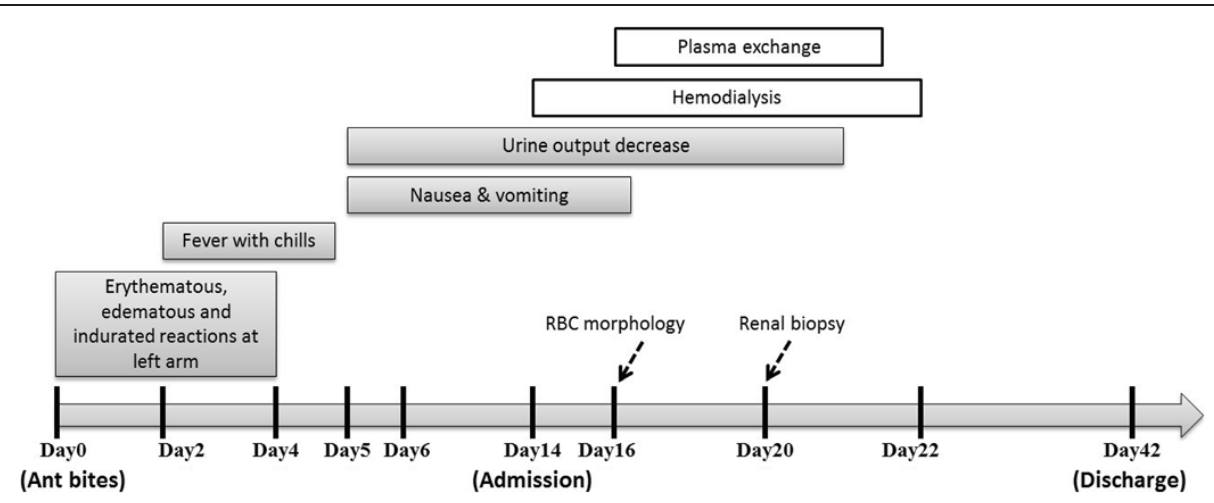

Figure 3 Timeline of the development of haemolytic-uremic syndrome following fire ant bites.

Formicidae (ants), Vespidae (wasps, hornets, and yellow jackets), and Apidae (honey bees and bumble bees) $[3,4]$. The venom composition of the IFA is complex, including several proteins capable of inducing allergy and anaphylaxis. In addition to these proteins, piperidine alkaloids are also present and are a major component of IFA venom (approximately 95\%) [5]. This component is not allergenic but is responsible for the local pain and pustules commonly experienced in ant bites. After fire ant bites, three different reactions may be elicited: local, large local, or systemic (anaphylaxis) [6-9]. A local reaction results in an immediate flare and wheal followed by a pustule after approximately 1 day. A large local reaction is an erythematous, oedematous, and indurated region extending beyond the pustule, which may last several days. The occurrence rate of serious systemic reactions is much rarer, at approximately $2 \%$.

The above complications relate to the biological activity of the ant venom, which causes cytotoxic, neurotoxic, and haemolytic reactions within the body $[10,11]$. It also activates coagulation and predisposes the individual to a hypercoagulable state [12-14]. Javors et al. discovered that fire ant venom alkaloids affect certain physiological and biochemical functions of human platelets and neutrophils in 1993 [14]. He found that venom alkaloids induced an increase in platelet intracellular calcium ion concentration $\left(\mathrm{Ca}^{2+}\right)$, secretion of dense granules, and aggregation. The aggregation response was less complete than that of the platelet-activating factor (PAF). Furthermore, pre-treatment of platelets with venom alkaloids produced enhanced PAF-related intracellular $\mathrm{Ca}^{2+}$ spiking, suggesting synergism between the two agonists. Venom alkaloids also induce an increase and accumulation of neutrophils and intracellular $\mathrm{Ca}^{2+}$. These results suggest that fire ant venom alkaloids do activate platelets and neutrophils. Therefore, platelet thrombi formation and endothelial injury may occur in vivo after fire ant bites. In fact, there is a report on a 5-day-old neonate developing microangiopathic haemolytic anaemia after fire ant bites [15]. These findings may partially explain the pathogenesis of HUS following exposure to fire ant venom. There are some case reports of HUS or ADAMTS-13 deficiency after scorpion sting [16-19]; however, to the best of our knowledge, there are no existing reports of HUS development as a result of ant bites.

The limitation of our report is that we cannot examine the complement regulators, genetic mutations, or ADAMTS 13 activity in this patient. Therefore, the possibility of atypical HUS and TTP cannot be completely excluded. The diagnosis of atypical HUS is substantially one of exclusion, based on evidences of microangiopathic hemolytic anemia (MAHA), thrombocytopenia, and renal failure, in the absence of infections by Shiga-toxin producing bacteria or other micro-organisms associated with HUS, of possible causes of secondary forms of HUS (such as medications, autoimmune diseases, and malignancy) and of reduced ADAMTS 13 activity (< 10\%) [20]. Atypical HUS designates a primary disease due to a disorder in complement alternative pathway regulation. The onset is from the neonatal period to adult [20,21]. At the first episode of HUS, about one-third of patients have progressed to end-stage renal disease and half of the patients have relapses. Gene mutations-including complement regulatory proteins thrombomodulin, factor $\mathrm{H}$, factor $\mathrm{I}$, and membrane cofactor protein (MCP) - have been demonstrated. Mutations in the genes for $\mathrm{C} 3$ convertase proteins, $\mathrm{C} 3$ and factor $\mathrm{B}$, as well as patients with anti-factor $\mathrm{H}$ antibodies, have also been reported [20,21]. The disease is familial in approximately $20 \%$ of pedigrees. Recent studies have showed that the complement abnormalities, such as reduced C3 levels, reflecting activation of complement alternative pathway, are found only in a subset of patients, and are not necessary to make the diagnosis of atypical HUS [20,22]. Although our patient didn't have HUS-like episodes family history and had normal serum C3, C4 levels, we still cannot rule out a putative role of complement dysregulation in the pathogenesis of this case. ADAMTS 13 activity is typically 
decreased or absent in thrombotic thrombocytopenic purpura (TTP) patients, and is a good marker for differential diagnosis between TTP and atypical HUS. There has been a case report of ADAMTS 13 deficiency after a scorpion sting and successful recovery after treatment by plasma exchange [19]. And, a consistent subset of patients with severe ADAMTS13 deficiency (e.g. 29\% in the series of 65 patients from the Oklahoma TTP-HUS Registry presented by JN George) has no neurological symptoms [23]. The clinical features of TTP are similar to those of our case, so we think although there were no neurologic symptoms (including headache, dysphasia, seizure, confusion, stupor, or coma) in our patient; TTP remains a possible differential diagnosis unless normal ADAMTS13 activity is proved.

\section{Conclusions}

We present the first case report of HUS and acute renal failure resulting from fire ant bites. The venom alkaloids of the ants may be responsible for the activation of platelets and neutrophils, the formation of platelet thrombi, endothelial injury, and ultimately the development of HUS. Although the possibility of atypical HSU and TTP cannot be completely excluded, this case still illustrates a serious systemic reaction of HUS to fire ant bites and highlights the need for awareness of this complication in patients who sustain fire ant bites.

\section{Consent}

Written informed consent was obtained from the patient for publication of this case report and any accompanying images.

\section{Abbreviations \\ CBC: Complete blood count; CK: Creatine kinase; HUS: Hemolytic-uremic syndrome; HBsAg: Hepatitis B surface antigen; Ig: Immunoglobulin; IFA: Imported fire ant; PAF: Platelet-activating factor; TTP: Thrombotic thrombocytopenic purpura.}

\section{Competing interests}

The authors declare that they have no competing interests.

\section{Authors' contributions}

All the authors were involved in the clinical management of the case and the writing of the report. All authors read and approved the final manuscript.

\section{Acknowledgements}

We are indebted to Shin-Han Tseng for critical discussion.

\footnotetext{
Author details

${ }^{1}$ Division of Nephrology, Department of Internal Medicine, E-Da Hospital/ I-Shou University, No.1, Yida Rd., Yanchao Dist., Kaohsiung City 824, Taiwan. ${ }^{2}$ Institute of Clinical Medicine, National Cheng Kung University Medical, Tainan, Taiwan. ${ }^{3}$ Department of Pathology, Kaohsiung Veterans General Hospital, Kaohsiung, Taiwan. ${ }^{4}$ Division of Nephrology, Department of Internal Medicine, Kaohsiung Armed Forces General Hospital, Kaohsiung, Taiwan.
}

\section{References}

1. McLigeyo SO: Haemolytic uraemic syndrome: a review. East Afr Med J 1999, 76:148-153.

2. Koya $S$, Crenshaw D, Agarwal A: Rhabdomyolysis and acute renal failure after fire ant bites. J Gen Intern Med 2007, 22:145-147.

3. Vetter RS, Visscher PK, Camazine S: Mass envenomations by honey bees and wasps. West J Med 1999, 170:223-227.

4. Steen CJ, Janniger CK, Schutzer SE, Schwartz RA: Insect sting reactions to bees, wasps, and ants. Int J Dermatol 2005, 44:91-94.

5. Brand JM, Blum MS, Fales HM, MacConnell JG: Fire ant venoms: comparative analyses of alkaloidal components. Toxicon 1972, 10:259-271.

6. Adams CT, Lofgren CS: Incidence of stings or bites of the red imported fire ant (Hymenoptera: Formicidae) and other arthropods among patients at Ft. Stewart, Georgia, USA. J Med Entomol 1982, 19:366-370.

7. Kundrotas L: Images in clinical medicine. Sting of the fire ant (Solenopsis). N Engl J Med 1993, 329:1317.

8. Tracy JM, Demain JG, Quinn JM, Hoffman DR, Goetz DW, Freeman TM: The natural history of exposure to the imported fire ant (Solenopsis invicta). J Allergy Clin Immunol 1995, 95:824-828.

9. Tankersley MS: The stinging impact of the imported fire ant. Curr Opin Allergy Clin Immunol 2008, 8:354-359.

10. Hoffman DR, Dove DE, Jacobson RS: Allergens in Hymenoptera venom. $X X$. Isolation of four allergens from imported fire ant (Solenopsis invicta) venom. J Allergy Clin Immunol 1988, 82:818-827.

11. deShazo RD, Butcher BT, Banks WA: Reactions to the stings of the imported fire ant. N Engl J Med 1990, 323:462-466.

12. Rhoades RB, Stafford CT, James FK Jr: Survey of fatal anaphylactic reactions to imported fire ant stings. Report of the fire ant subcommittee of the American academy of allergy and immunology. J Allergy Clin Immunol 1989, 84:159-162.

13. deShazo RD, Banks WA: Medical consequences of multiple fire ant stings occurring indoors. J Allergy Clin Immunol 1994, 93:847-850.

14. Javors MA, Zhou W, Maas JW Jr, Han S, Keenan RW: Effects of fire ant venom alkaloids on platelet and neutrophil function. Life Sci 1993, 53:1105-1112.

15. Hardwick WE, Royall JA, Petitt BA, Tilden SJ: Near fatal fire ant envenomation of a newborn. Pediatrics 1992, 90:622-624.

16. Valavi E, Ansari MJ: Hemolytic uremic syndrome following Hemiscorpius lepturus (scorpion) sting. Indian J Nephrol 2008, 18:166-168.

17. Bahloul M, Ben Hmida M, Belhoul W, Ksibi H, Kallel H, Ben Hamida C, Chaari A, Chelly H, Rekik N, Bouaziz M: Hemolytic-uremic syndrome secondary to scorpion envenomation (apropos of 2 cases). Nephrologie 2004, 25:49-51.

18. Mocan H, Mocan MZ, Kaynar K: Haemolytic-uraemic syndrome following a scorpion sting. Nephrol Dial Transplant 1998, 13:2639-2640.

19. Valavi E, Ansari MJ, Hoseini S: ADAMTS-13 deficiency following Hemiscorpius lepturus scorpion sting. Saudi J Kidney Dis Transpl 2011, 22:792-795.

20. Loirat C, Fremeaux-Bacchi V: Atypical hemolytic uremic syndrome. Orphanet $J$ Rare Dis 2011, 6:60.

21. Tsai HM: Untying the knot of thrombotic thrombocytopenic purpura and atypical hemolytic uremic syndrome. Am J Med 2013, 126:200-209.

22. Legendre CM, Licht C, Muus P, Greenbaum LA, Babu S, Bedrosian C, Bingham C, Cohen DJ, Delmas Y, Douglas K, Eitner F, Feldkamp T, Fouque D, Furman RR, Gaber O, Herthelius M, Hourmant M, Karpman D, Lebranchu Y, Mariat C, Menne J, Moulin B, Nurnberger J, Ogawa M, Remuzzi G, Richard T, Sberro-Soussan R, Severino B, Sheerin NS, Trivelli A, Zimmerhackl LB, Goodship T, Loirat C: Terminal complement inhibitor eculizumab in atypical hemolytic-uremic syndrome. N Engl J Med 2013, 368:2169-2181.

23. George JN: How I treat patients with thrombotic thrombocytopenic purpura: 2010. Blood 2010, 116:4060-4069.

doi:10.1186/1471-2369-15-5

Cite this article as: Lee et al:: Haemolytic uremic syndrome following fire ant bites. BMC Nephrology 2014 15:5. 